\title{
Small crown-ether complexes as molecular models for dihydrogen adsorption in undercoordinated extraframework cations in zeolites
}

\author{
Toshiki Wulf $f^{+,}$, Thomas Heine $e^{*,+, \S}$ \\ †Wilhelm-Ostwald-Institut für Physikalische und Theoretische Chemie, Linnéstraße 2, 04103 Leipzig, Germany \\ ‡TU Dresden, Fakultät für Chemie und Lebensmittelchemie, Bergstraße 66c, 01062 Dresden, Germany \\ ${ }^{\S}$ Helmholtz-Zentrum Dresden-Rossendorf, Forschungsstelle Leipzig, Permoserstraße 15, 04318 Leipzig, Germany
}

\begin{abstract}
: 1:1 metal complexes of small crown-ethers are structurally similar to extraframework sites in metal-exchanged zeolites. Using $a b$ initio calculations, we show that adsorbed molecular hydrogen follows the same trends in adsorption energies and vibrational frequencies at both types of metal sites. Unlike zeolites, crown-ethers can be characterized in the gas phase, which opens new possibilities for understanding the bonding of dihydrogen at undercoordinated metal sites to help guide the rational design of porous materials for hydrogen isotope separation. Because more strongly binding adsorbates affect the geometry of the hosts, the similarity of crown-ethers and zeolites with regard to the vibrational spectra of the adsorbed molecule seems to be limited to $\mathrm{H}_{2}$.
\end{abstract}

\section{Introduction}

Since their adoption as catalysts, zeolites have revolutionized many industrial chemical processes. ${ }^{1-5}$ Their widespread use has attracted great interest in these alumosilicate materials and there has been a substantial growth in the scientific knowledge base on zeolites. Much of this progress has been achieved by combining experiments with reliable theoretical calculations, which have been possible only due to the substantial growth in both computational power and innovative methodologies we have seen since the turn of the century. ${ }^{6-8}$

Zeolites are porous silicates where framework $\mathrm{Al}$ substitutes some of the tetrahedral ( $\mathrm{Si}$ ) sites. This creates a negative framework charge that is compensated by positive counter ions, which are relatively flexible in their movement and are often strongly undercoordinated. $\mathrm{H}_{2}$ with its stretch vibration has proved to be a very sensitive probe for these sites and extremely strong adsorption with isosteric heats of adsorption up to $8 \mathrm{o} \mathrm{kJ} \cdot \mathrm{mol}^{-1}$ at $\mathrm{Cu}^{+}$has been reported..$^{-11}$ Data from inelastic neutron scattering indicates a strong end-on binding of $\mathrm{H}_{2}$ at extraframework $\mathrm{Cu}^{+}$and is consistent with a rigid rotor confined to rotation in the plane normal to the coordination vector. ${ }^{12}$

Zeolites are complex materials with considerable unit cell sizes and often high degrees of disorder. The wealth of different adsorption sites complicates unambiguous assignment of spectroscopic data to individual sites. After initial contradictory reports on the positions of cations and the inferred positions of framework $\mathrm{Al}$ sites, especially in complex zeolites like ZSM-5, ${ }^{13-15}$ there seems to be consensus that $\mathrm{Al}$ siting in zeolites is neither thermodynamically controlled nor random, but unpredictable and strongly dependent on the conditions of the synthesis. . $^{13,15,16}$
As is evident by the number of applications of shape-selective catalysis, the mechanisms of reactions inside zeolites often strongly depend on the structure of and the confinement around the active sites. ${ }^{17}$ Furthermore, accurate computational studies on zeolites and their reaction mechanisms require knowledge of and therefore often need to make assumptions about $\mathrm{Si} / \mathrm{Al}$ ratio, $\mathrm{Al}$ siting, the distribution of $\mathrm{Al}-\mathrm{Al}$ interatomic distances and the position of extraframework cations. ${ }^{15}$

As a consequence, even the seemingly simple case of small-molecule gas adsorption at exposed extraframework metal sites in zeolites is complex: Discerning which effects stem from the metal center itself (effect from bottom) and which from the confinement or interaction with the framework (effect from top) is non-trivial and has been a matter of debate..$^{18,19}$

These complications have led to a search for well-defined molecular models that resemble zeolite frameworks. Such systems have been investigated in both the liquid and the gas phase. ${ }^{20,21}$ However, to the best of our knowledge, other than naked metal ions, ${ }^{22,23}$ no molecular models have been proposed for zeolitic extraframework cations. Such a model would be especially useful for gas-phase vibrational studies, because it would avoid the multitude of slightly different metal sites in the same zeolite. ${ }^{24}$

Here, we argue that small crown-ether complexes are good models for such sites, especially in the case of highly undercoordinated $\mathrm{Cu}^{+}$. We also include the other coinage metal ions with $\mathrm{d}^{10}$ configurations, $\mathrm{Ag}^{+}$and $\mathrm{Au}^{+} . \mathrm{Li}^{+}$is investigated as an ion with a radius similar to that of $\mathrm{Cu}^{+}$but no $\mathrm{d}$ orbitals; this allows for an estimation of the extent of the influence of $\pi$ backdonation, which is present in $\mathrm{Cu}^{+}$ but not in $\mathrm{Li}^{+}$. 
Similarities between the coordination behaviors of zeolites and crown-ethers have been reported before. Ozin and Özkar pointed out the analogy between 4-rings (6rings) in high-alumina zeolites and 12-crown-4 (18-crown6) with respect to undercoordinated organometallic species. ${ }^{25}$ In high-silica zeolites where there is a high degree of localization of the framework negative charge, however, extraframework cations prefer close proximity to one specific $\mathrm{AlO}_{4}$ unit rather than a central position in a ring. When this metal cation is naked (which is typical for monovalent ions), this comes with an extremely high degree of undercoordination of the metal cation, which results in a very strong adsorption of host molecules. ${ }^{11}$

In the present article, we show that small crown-ethers behave similar to $\mathrm{AlO}_{4}$ units and that the backbone of the cationic metal site plays a minor role with regard to its local geometry and the adsorption of $\mathrm{H}_{2}$. We outline that, for the particular case of $\mathrm{H}_{2}$, even molecular models with organic ligands describe the local adsorption energetics surprisingly well. We conclude that small crown-ethers are suitable zeolite-analogous molecular model systems for $\mathrm{H}_{2}$ adsorption.

Since crown-ether metal complexes are small cationic species, this opens up the possibility of studying pertinent $\mathrm{H}_{2}$ adsorption complexes in the gas phase, for example in an ion trap. The interpretation of experimental data is facilitated by their simplicity, the fact that they have only one possible metal site and the absence of effects from the top. This offers the opportunity to identify which role specific extraframework cationic adsorption sites play for $\mathrm{H}_{2}$ adsorption in the complex environment of a zeolite. At the same time, their limited size allows for a high-level computational treatment.

To quantify the similarity of our target systems, we will focus on harmonic vibrational frequencies as a sensitive measure of the chemical environment. The use of this particular benchmark is in part motivated by our desire for a deeper understanding of the isotopologue-selective adsorption of $\mathrm{H}_{2}$ at undercoordinated metal sites, a phenomenon that is driven by the differences in vibrational zeropoint energy (ZPE). While we will show that cationic metal-crown-ether complexes indeed show very similar $\mathrm{H}_{2}$ adsorption properties compared to corresponding sites in zeolites, this analogy does not extend to other molecules, as for example CO.

\section{Results}

\section{Model systems and number of oxygen donor atoms}

As the smallest regular crown-ether, 9-crown-3 (9c3) has been the focus of our study. To investigate the sensitivity of the bonding situation on the coordination geometry and to determine the extent to which size effects play a role, also 1,4-dioxane (6c2), 1,4-dioxacycloheptane (7c2) and 1,5dioxacyclooctane $(8 \mathrm{c} 2)$ have been included. All of them are decorated with a metal cation, so that the overall system carries a single positive charge. Being cations makes these species ideally suited for single-molecule experiments in ion traps.
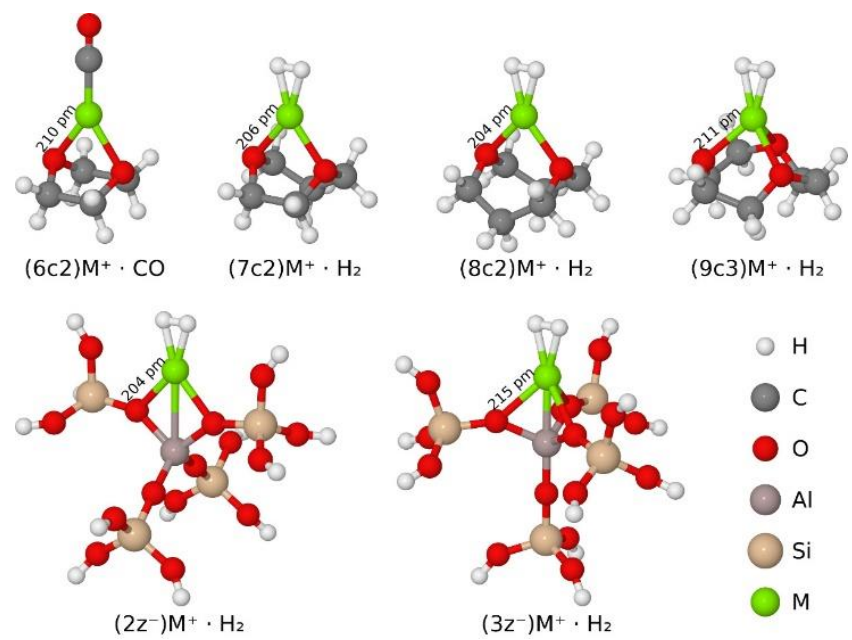

$(9 \mathrm{c} 3) \mathrm{M}^{+} \cdot \mathrm{H}_{2}$

Figure 1. Atomistic models with adsorbed molecules at representative positions and $\mathrm{M}-\mathrm{O}$ bond lengths for $\mathrm{M}^{+}=\mathrm{Cu}^{+}$. Top: crown-ethers 6-crown-2 to 9-crown-3; bottom: 5 T zeolite cluster models with an extraframework metal ion that is centered above the edge (left) or face (right) formed by two or three oxygen atoms of the $\mathrm{AlO}_{4}$ tetrahedron, respectively.

Two zeolite model clusters with five tetrahedral sites (5T) and one extraframework cation have been selected as benchmark models: one in which the cation is coordinated by two $(2 \mathrm{z})$ and one where it is coordinated by three $(3 \mathrm{z})$ of the oxygen atoms of the central $\mathrm{AlO}_{4}$ tetrahedron (see Figure 1). While environments similar to $2 \mathrm{z}$ can be found in eight-membered (e.g. in CHA or LTA) and twelve-membered rings (LTL) and 3z-like motifs can be found in the toc unit (supercage) of FAU or in the grc unit ( $\alpha$ cage) of LTA, these particular models have been chosen as the extremes between which most extraframework sites in zeolites lie.

\section{Similarities in geometric and electronic structure}

Table 1. Geometrical parameters of the local structure around the metal site in the studied model systems for $\mathrm{M}^{+}=\mathrm{Cu}^{+}$(all without adsorbed gas).

\begin{tabular}{ccccc}
\hline & $\begin{array}{c}r_{\mathrm{Cu}-\mathrm{O}} \\
\mathrm{pm}\end{array}$ & $\begin{array}{c}r_{\mathrm{O}-\mathrm{O}} \\
\mathrm{pm}\end{array}$ & $\begin{array}{c}\varphi_{\mathrm{O}-\mathrm{Cu}-\mathrm{O}} \\
\circ\end{array}$ & $\begin{array}{c}E_{\text {bind, } \mathrm{Cu}} \\
\mathrm{kJ} \cdot \mathrm{mol}^{-1}\end{array}$ \\
\hline $6 \mathrm{c2}$ & 212 & 245 & 70.8 & -242 \\
$7 \mathrm{c} 2$ & 208 & 257 & 76.0 & -273 \\
$8 \mathrm{c} 2$ & 205 & 270 & 82.6 & -299 \\
$9 \mathrm{c} 3$ & 215 & 277 & 80.1 & -334 \\
$2 \mathrm{Z}$ & 204 & 268 & 82.5 & -757 \\
$3 \mathrm{Z}$ & 226 & 273 & 74.5 & -714 \\
\hline
\end{tabular}

It is immediately apparent from Figure 1 that the local structure of the metal site and the oxygen donor atoms are very similar between the crown-ethers and the zeolite models. Taking $\mathrm{Cu}^{+}$as an example, 
Table 2 shows that the geometrical parameters of $8 \mathrm{c} 2$ almost perfectly match those of $2 \mathrm{z} .3 \mathrm{z}$ is best matched by $9 \mathrm{c} 3$ - however, with a $\mathrm{Cu}-\mathrm{Al}$ distance of $235 \mathrm{pm}$ (as compared to a sum of covalent radii of $253 \mathrm{pm}$ ), the geometry of $3 \mathrm{Z}$ is strongly influenced by the $\mathrm{Cu}-\mathrm{Al}$ repulsion, which prevents the $\mathrm{Cu}^{+}$ion from moving as close to the plane of the oxygen atoms as in the 9c3 model. This results in a slightly larger $\mathrm{Cu}-\mathrm{O}$ distance $(226 \mathrm{pm} v s 215 \mathrm{pm})$ and a more acute $\mathrm{O}-\mathrm{Cu}-\mathrm{O}$ angle $\left(74.5^{\circ}\right.$ vs $\left.80.1^{\circ}\right)$.

Overall, however, both $\mathrm{Cu}-\mathrm{O}$ distances and $\mathrm{O}-\mathrm{Cu}-\mathrm{O}$ angles are similar in the crown-ether and zeolite models, with a slight trend to larger $\mathrm{Cu}-\mathrm{O}$ distances for larger rings and coordination by more $\mathrm{O}$ atoms. The $\mathrm{O}-\mathrm{O}$ distances follow the same trend, though more pronounced in the crownethers. The $\mathrm{Cu}^{+}$binding energy increases for the crownethers with the ring size as bond angle strain decreases, and is significantly stronger for the zeolite models due to the additional interaction with the Lewis base site.

Table 2 shows the results of a Bader analysis for $\mathrm{Cu}^{+}$systems, which confirm that the electronic structures are very similar between the adsorption complexes of $\mathrm{H}_{2}$ with crown-ethers and the zeolites. The Bader charges at the acidic $\mathrm{Cu}$ sites slightly decrease with the ring size in the crown-ether cations, which is in line with the expectation that their greater size should allow for a stronger delocalization of the charge. The charge is slightly smaller for the zeolites than for the crown-ethers, which is readily rationalized by the fact that these systems are charge-neutral, whereas the crown-ether complexes have a net positive charge. Accordingly, $\mathrm{H}_{2}$ that binds to the metal is more strongly positively polarized at the crown-ethers as compared to the zeolites.

Bonds can be defined by the existence of bond critical points (BCPs), i.e. points in space that represent an electron density minimum along one direction (the direction of the bond) and a maximum in the plane normal to the bond direction. The systems with alkali metals, $\mathrm{Cu}^{+}$and $\mathrm{Ag}^{+}$exhibit a BCP in the middle of the $\mathrm{H}_{2}$ molecule and another one between the metal center and the $\mathrm{H}_{2}$. By contrast, all $\mathrm{Au}^{+}$systems instead have BCPs in between the metal center and the individual $\mathrm{H}$ atoms, indicating that $\mathrm{Au}^{+}$systems are dihydrides rather than dihydrogen complexes.

Table 2. Bader charges of the model systems for $\mathrm{M}^{+}=\mathrm{Cu}^{+}$without and with adsorbed $\mathrm{H}_{2}$, its change upon $\mathrm{H}_{2}$ adsorption and the charge of adsorbed $\mathrm{H}_{2}$; electron density and its Laplacian at the bond critical point between the two $\mathrm{H}$ atoms of the adsorbed $\mathrm{H}_{2}$; electron density and Laplacian at the bond critical point between $\mathrm{Cu}^{+}$and $\mathrm{H}_{2}$ and distance of that bond critical point from $\mathrm{Cu}^{+}$.

\begin{tabular}{|c|c|c|c|c|c|c|c|c|c|}
\hline & $\begin{array}{c}q_{\mathrm{Cu}} \\
e\end{array}$ & $\begin{array}{c}q_{\mathrm{Cu} \mathrm{w/H} 2} \\
e\end{array}$ & $\begin{array}{c}\Delta_{\mathrm{ad}} q_{\mathrm{Cu}} \\
e\end{array}$ & $\begin{array}{c}q_{\mathrm{H} 2 @ \mathrm{Cu}} \\
e\end{array}$ & $\begin{array}{l}\rho_{\mathrm{BCP} \mathrm{H}-\mathrm{H}} \\
e / r_{\text {Bohr }^{-3}}\end{array}$ & $\begin{array}{c}\nabla^{2} \rho_{\text {BCP H-H }} \\
e \cdot r_{\text {Bohr }}^{-5}\end{array}$ & $\begin{array}{c}\rho_{\mathrm{BCP} \mathrm{Cu}-\mathrm{H}_{2}} \\
e \cdot r_{\mathrm{Bohr}}{ }^{-3}\end{array}$ & $\begin{array}{c}\nabla^{2} \rho_{\mathrm{BCP} \text { Cu}} \\
{ }_{\mathrm{H} 2} \\
e \cdot r_{\mathrm{Bohr}}{ }^{-5}\end{array}$ & $\begin{array}{c}\mathrm{Z}_{\mathrm{BCP} \mathrm{Cu}-\mathrm{H}_{2}} \\
\mathrm{pm}\end{array}$ \\
\hline $6 c 2$ & +0.812 & +0.751 & -0.061 & +0.068 & 0.230 & -0.914 & 0.097 & 0.348 & 97.4 \\
\hline $7 \mathrm{C} 2$ & +0.809 & +0.752 & -0.057 & +0.058 & 0.228 & -0.890 & 0.099 & 0.354 & 97.1 \\
\hline $8 \mathrm{c} 2$ & +0.801 & +0.755 & -0.046 & +0.050 & 0.227 & -0.878 & 0.100 & 0.357 & 97.1 \\
\hline $9 \times 3$ & +0.794 & +0.748 & -0.046 & +0.050 & 0.230 & -0.907 & 0.098 & 0.356 & 97.4 \\
\hline $2 \mathrm{Z}$ & +0.770 & +0.760 & -0.010 & +0.011 & 0.227 & -0.865 & 0.101 & 0.371 & 97.1 \\
\hline $3 z$ & +0.784 & +0.755 & -0.030 & +0.028 & 0.233 & -0.934 & 0.094 & 0.352 & 98.1 \\
\hline
\end{tabular}

The position of the BCPs and the electron density and its Laplacian at these points further corroborate the electronic similarities of the systems studied. For all of these quantities the values from the crown-ethers either lie in the range spanned by the two zeolite models or are very close to it (see Table 2 for $\mathrm{Cu}^{+}$and Figure 2 for all metals except $\mathrm{Au}^{+}$).

(a)

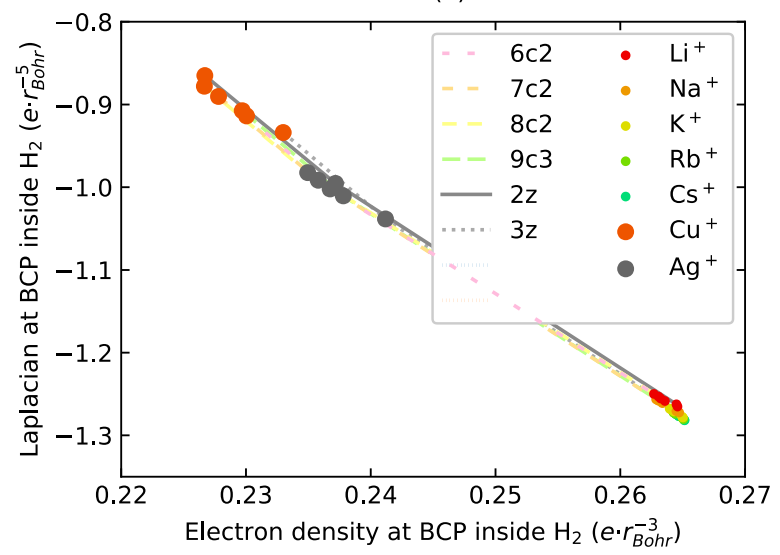

(b)

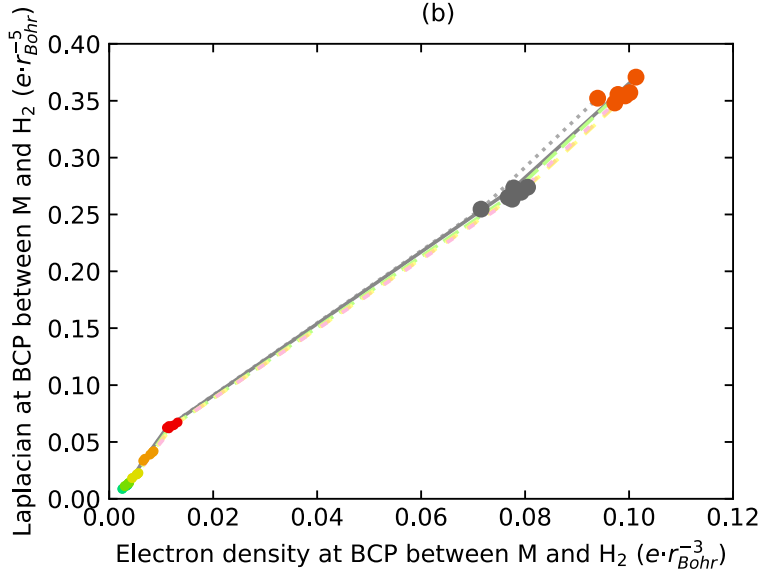

Figure 2. Electron densities and Laplacians in the systems studied at the bond critical points (a) inside the adsorbed $\mathrm{H}_{2}$ molecule and (b) between the metal center and the $\mathrm{H}_{2}$ molecule. 

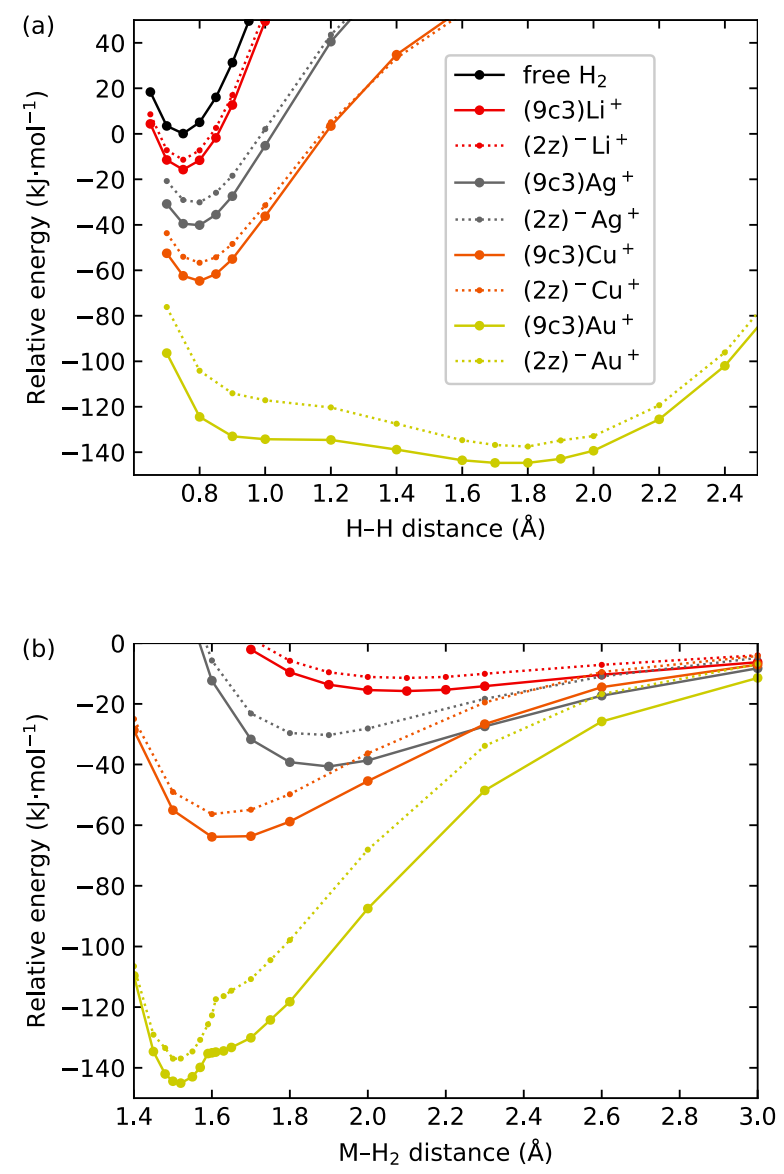

Figure 3. DLPNO-CCSD(T) potential energy surface scans along (a) the $\mathrm{H}-\mathrm{H}$ and (b) $\mathrm{M}-\mathrm{H}_{2}$ distance coordinates for $\mathrm{Li}^{+}$ and monovalent coinage metals. $\mathrm{Li}^{+}, \mathrm{Ag}^{+}$and $\mathrm{Cu}^{+}$, in this order, show a trend of stronger $\mathrm{H}_{2}$ adsorption and equilibrium bond elongation. By contrast, $\mathrm{Au}^{+}$exhibits a qualitatively different behavior, adding $\mathrm{H}_{2}$ as a dihydride (see text). Colors denote the same systems in both plots. Raw data is given in the Supporting Information.

$\mathrm{H}_{2}$ coordinates side-on to all investigated model cations. Whereas alkali cations form classical dihydrogen adsorption complexes, the coinage metals activate $\mathrm{H}_{2}$ more strongly: $\mathrm{Cu}^{+}$and $\mathrm{Ag}^{+}$form Kubas-type complexes with dihydrogen bond lengths of 79 to $81 \mathrm{pm}$. A stronger bonding for these $\mathrm{d}^{10}$ metals is expected because the filled $\mathrm{d}$ orbitals can engage in $\pi$ backdonation and thereby lead to a much stronger interaction.

Except for $\mathrm{Au}^{+}$, the coinage metals follow the same qualitative trends as the alkali metals but show a much stronger interaction. This is in line with the fact that there is no distinctive fundamental difference between van der Waals and Kubas complexes and a fluid transition between the two. ${ }^{26}$

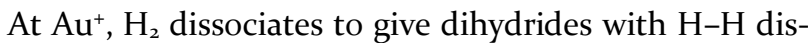
tances of 170 to $190 \mathrm{pm}$. Furthermore, the potential energy curve along the $\mathrm{H}-\mathrm{H}$ distance coordinate is very shallow for adsorption at $\mathrm{Au}^{+}$(see Figure 3). This also causes the irregular shape of the potential curve along the $\mathrm{M}-\mathrm{H}_{2}$ distance coordinate, because as the $\mathrm{M}-\mathrm{H}_{2}$ distance increases, the complex passes from the dihydride regime to the Kubas regime.

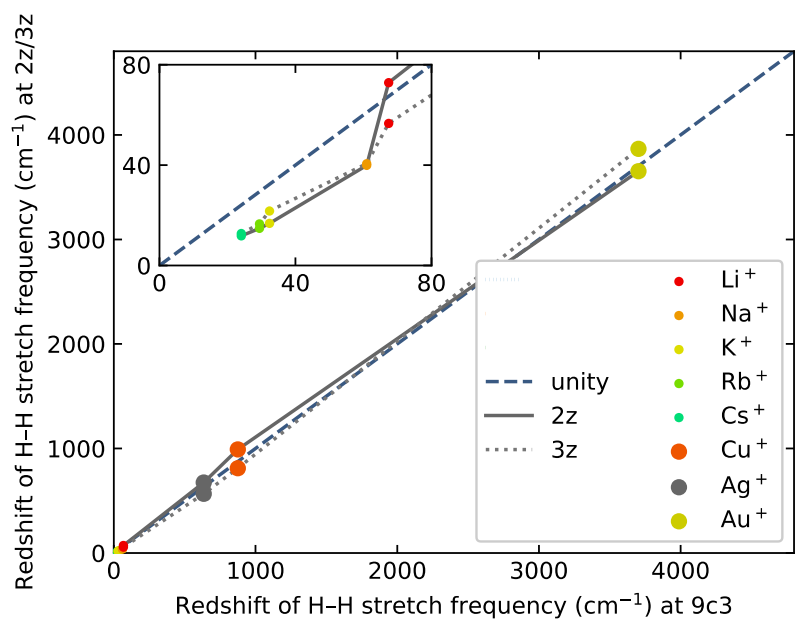

Figure 4. Correlation of the shift of the $\mathrm{H}-\mathrm{H}$ stretch frequency between the molecular 9-crown-3 model system and the zeolite cluster models. A log-log chart can be found in the Supporting Information (Figure $\mathrm{S}_{1}$ ). A similar correlation is found for the $\mathrm{H}_{2}$ adsorption energies (Figure $\mathrm{S}_{2}$ ).

\section{Vibrational frequencies of adsorbed dihydrogen}

Both zeolite cluster models give nearly identical $\mathrm{H}-\mathrm{H}$ stretch frequencies (see Figure $4, \mathrm{R}^{2}$ of unity line in excess of 0.99 ) and $\mathrm{H}_{2}$ adsorption energies ( $\mathrm{R}^{2}$ in excess of 0.96$)$. The crown-ether cation complexes adsorb more strongly, which would be expected due to their net positive charge. Within the crown-ether series, there is a general trend of slightly weaker $\mathrm{H}_{2}$ adsorption towards larger crown-ethers. This is in line with a stronger localization of the positive charge and a more acute bite angle for the smaller ligands, which decreases the stability of the complex and increases the attraction of the gas molecule. Since all these effects best cancel for 9c3, these complexes - especially those of the coinage metals - behave most similarly to the zeolite models.
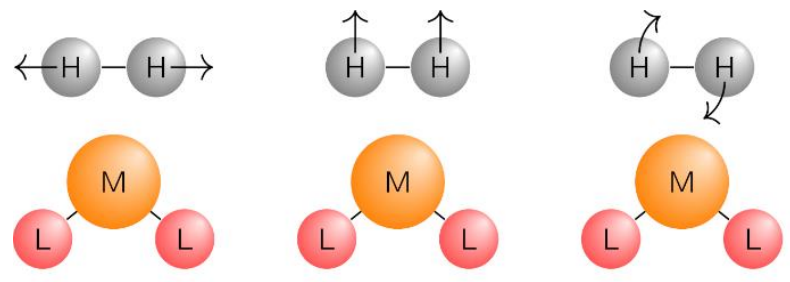

$\mathrm{H}-\mathrm{H}$ stretch

$$
\mathrm{M}-\mathrm{H}_{2} \text { stretch }
$$

hindered

$$
\mathrm{M}-\mathrm{H}_{2} \text { rotation }
$$

Figure 5. Sketch of vibrational modes of molecular $\mathrm{H}_{2}$ adsorbed at a metal center. 
Figure 5 shows the three vibrational modes of adsorbed $\mathrm{H}_{2}$. Their frequencies can be used as measures of the magnitude of the interaction with the metal cation: the $\mathrm{H}-\mathrm{H}$ stretch frequency, $v_{\mathrm{H}-\mathrm{H}}$, the $\mathrm{M}-\mathrm{H}_{2}$ stretch frequency, $v_{\mathrm{M}-\mathrm{H}_{2}}$, and the frequency of the hindered rotation of the $\mathrm{H}_{2}$ about its center in the $\mathrm{M}-\mathrm{H}_{2}$ plane, $\delta_{\mathrm{M}-\mathrm{H}_{2}}$. Except for $\mathrm{Au}^{+}$(for details see below), the $\mathrm{H}-\mathrm{H}$ stretch frequency shows an almost linear negative correlation with the adsorption energy across the cations and ligand spheres studied in this work (see Figure 6). For the other two vibrational modes, there is a positive correlation with adsorption energy; this effect is strongest at the low end and stronger adsorption leads to progressively smaller increases in vibrational frequency. The exception to this rule are the $\mathrm{Au}^{+}$systems. Being dihydrides rather than complexes of molecular dihydrogen, these systems are qualitatively different, and this effect is seen in the vibrational modes as well. Therefore, $v_{\mathrm{M}-\mathrm{H}_{2}}$ and $\delta_{\mathrm{M}-\mathrm{H}_{2}}$ are more correctly characterized as $v_{\mathrm{MH}, \mathrm{symm}}$ and $v_{\mathrm{MH} \text {,asymm }}$ for these $\mathrm{Au}^{+}$systems, respectively. For $\mathrm{Au}^{+}$, especially $v_{\mathrm{MH}, \mathrm{symm}}$ is much higher than $v_{\mathrm{M}-\mathrm{H}_{2}}$ is in $\mathrm{Cu}^{+}$, but this comes with a very low value of $\delta_{\mathrm{HMH}}$ (which corresponds to the $v_{\mathrm{H}-\mathrm{H}}$ mode in the other systems).

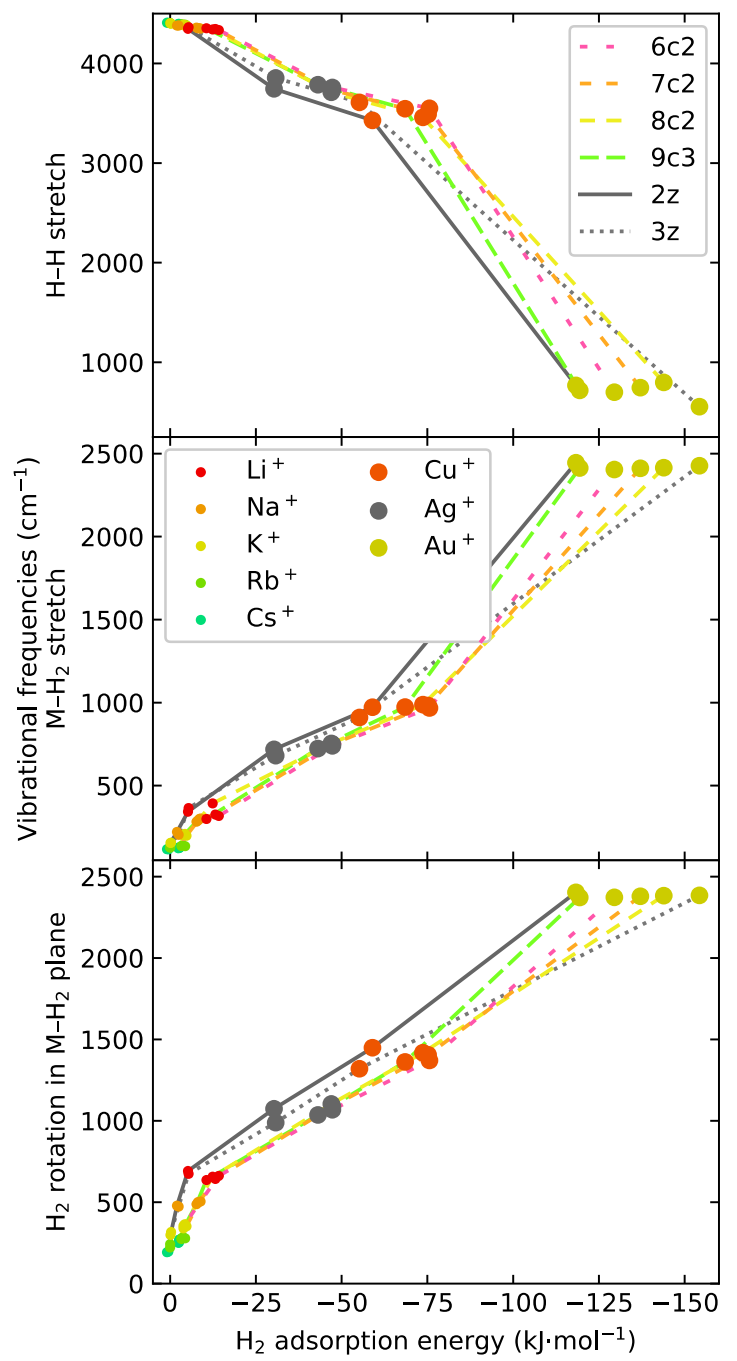

Figure 6. Scatter plot of the $\mathrm{H}-\mathrm{H}$ stretch frequency, $v_{\mathrm{H}-\mathrm{H}}$, the $\mathrm{M}-\mathrm{H}_{2}$ stretch frequency, $v_{\mathrm{M}-\mathrm{H}_{2}}$, and the frequency of the hindered rotation of the $\mathrm{H}_{2}$ about its center in the $\mathrm{M}-\mathrm{H}_{2}$ plane, $\delta_{\mathrm{M}-\mathrm{H}_{2}}$, vs. the adsorption energy of $\mathrm{H}_{2}$. Note that lines are only given to assign the data points to the models as $\mathrm{Au}^{+}$shows qualitatively different behavior (see text).

The extreme weakening of the $\mathrm{H}-\mathrm{H}$ bond, which results in a low $\delta_{\mathrm{HMH}}$ frequency, also causes $\mathrm{Au}^{+}$to have a lower $\mathrm{H}_{2}$ adsorption energy than $\mathrm{Cu}^{+}$. Therefore, even though $\mathrm{Au}^{+}$ has a higher $\mathrm{H}_{2}$ adsorption energy, $\mathrm{Cu}^{+}$has the highest adsorption ZPE of all metal cations investigated.

\section{Comparison with experimental data}

For ZSM-5 exchanged with $\mathrm{Cu}^{+}$and $\mathrm{Li}^{+}$, experimental $\mathrm{H}-$ $\mathrm{H}$ frequency shifts (with reference to free $\mathrm{H}_{2}$ ) of $-1079 \mathrm{~cm}^{-1}$ and $-69 \mathrm{~cm}^{-1}$, respectively, have previously been reported.9,27 The harmonic shifts of $-992 \mathrm{~cm}^{-1}$ and $-73 \mathrm{~cm}^{-1}$ we obtain for these same metal ions using our $2 \mathrm{z}$ zeolite cluster model are in good agreement with those data. However, given our neglect of anharmonic effects, one would expect our calculations to overestimate the magnitude of the red shift rather than to underestimate it. This suggests some form of fortuitous error cancellation in our calculations.

For the zeolite cluster models we obtain an $\mathrm{H}_{2}$ adsorption enthalpy of approximately $-5 \mathrm{~kJ} \cdot \mathrm{mol}^{-1}$ at $\mathrm{Li}^{+}$and -59 $\mathrm{kJ} \cdot \mathrm{mol}^{-1}$ at $\mathrm{Cu}^{+}$(2z model), which is in reasonable agreement with experimental results of $-4.1 \mathrm{~kJ} \cdot \mathrm{mol}^{-1}$ and -73 $\mathrm{kJ} \cdot \mathrm{mol}^{-1}$, respectively. ${ }^{11,28}$

\section{Extension of the analogy beyond $\mathrm{H}_{2}$ adsorption}

Because the $\mathrm{H}_{2}$ adsorption behavior between zeolite systems and the crown-ethers investigated here is so similar, it is interesting to investigate whether this also holds for other adsorbed species. While a thorough examination of this question is beyond the scope of this work, some preliminary data for $\mathrm{CO}$ and ethene are given in the supporting information. There, we conclude that the strict analogy found for $\mathrm{H}_{2}$ does not hold for other small molecules.

\section{Influence of the net charge and extension to metal ions with higher charges}

We attribute the stronger adsorption at crown-ethers as compared to zeolites to the net positive charge of the former and find it therefore remarkable how well the analogy carries quantitatively. However, for doubly and triply charged cations (such as $\mathrm{Mg}^{2+}, \mathrm{Mn}^{2+}$ or $\mathrm{Fe}^{3+}$ ), the strong positive charge leads to much higher adsorption energies when comparing the crown-ethers with charge-neutral complexes. Therefore, our findings are restricted to singly charged cations.

\section{Conclusion}

Small crown-ether complexes of metal ions share a strong analogy to binding motifs of extraframework cations in zeolites as evidenced by similar binding geometries, adsorption energies and vibrational frequencies. They capture the electronic effects that occur during adsorption at zeolites without showing shape selectivity and other effects from top. This opens the possibility to use them as 
molecular proxies in zeolite-related research aimed at understanding the fundamental mechanisms of $\mathrm{H}_{2}$ adsorption at the microscopic level. The simplicity of these systems further allows for facile application of computational approaches and allows validating methods for future application to more sophisticated models of the target materials.

As gas-phase species, crown-ether model systems could be investigated in ion-trap adsorption studies using infrared photodissociation techniques. In a combined approach with computational work, similar to previous studies, ${ }^{22,29,30}$ this would allow deep insights into the molecular vibrations and the influence of anharmonic vibrational effects on dihydrogen adsorption zero-point energy in realistic model systems resembling target sites in zeolitic materials. Further knowledge in this area is critical to future research aiming at more effective dihydrogen isotopologue separation at undercoordinated metal sites in porous materials such as zeolites and metal-organic framework (MOFs).

\section{Methods}

Quantum-chemical calculations except for Bader analysis were performed using the ORCA program system, version 4.0.1.2. ${ }^{11,32}$ Density functional theory calculations employed the hybrid functional PBEo ${ }^{33}$ corrected for dispersion interaction using Grimme's empirical model D3 with Becke-Johnson damping, ${ }^{34}$ commonly referred to as $\mathrm{D}_{3}(\mathrm{BJ})$. Ahlrichs basis sets including effective core potentials for heavy elements ${ }^{35}$ were used throughout the calculations: def2-TZVP basis was used for geometry optimizations and vibrational frequency calculations; single-point energies were obtained at the def2-QZVP level.

The generic zeolite cluster models were derived from the AST framework, obtained from the IZA structure database.$^{36} \mathrm{~A}$ cluster with $\mathrm{T}_{\mathrm{d}}$ symmetry was prepared by placing an $\mathrm{Al}$ atom at one $\mathrm{T}^{2}$ site, including adjacent $\mathrm{T}^{1}$ sites as $\mathrm{Si}$ atoms and the next shell of $\mathrm{T}^{2}$ sites as terminal $\mathrm{H}$ atoms, keeping the bond orientation fixed while adjusting the $\mathrm{O}-$ $\mathrm{H}$ bond length to $95 \mathrm{pm}$. The two different cluster models, $2 \mathrm{z}$ and $3 \mathrm{z}$, were obtained by bending two or three of the $\mathrm{Al}-\mathrm{O}-\mathrm{Si}$ angles to $160^{\circ}$ with dihedral angles that yield maximally symmetrical structures with $C_{2 v}$ and $C_{3 v}$ symmetry, respectively. For each combination of extraframework ion and cluster model, the metal ion was placed onto the symmetry axis to yield an extraframework cation centered at the edge or the face of the $\mathrm{AlO}_{4}$ tetrahedron, respectively. These structures were relaxed in constrained geometry optimizations with the terminal $\mathrm{OH}$ groups frozen in space.

To improve the stability of the geometry optimizations, we found it expedient to fix the zeolite structures (including the position of the extraframework cation) upon adsorption of the probe molecule. Previous studies showed that such modeling with a frozen adsorption site structure gives reliable adsorption energies. ${ }^{37,38}$ To confirm that this also applies for the significantly higher adsorption energies of the $\mathrm{Cu}^{+}$and $\mathrm{Au}^{+}$complexes reported here, we compared the fully relaxed structures of the adsorption complex with those in which only the $\mathrm{H}_{2}$ molecule was relaxed. Figure $\mathrm{S}_{3}$ shows the validity of the frozen adsorption-site approach for $\mathrm{H}_{2}$ complexes involving Kubas-type $\left(\mathrm{Cu}^{+}, \mathrm{Ag}^{+}\right)$and weaker bonding (alkali metals). However, as a result of their very shallow $\mathrm{PES}$, the $\mathrm{Au}^{+}$complexes give significantly different results for the two methodologies; most notably the $\mathrm{H}-\mathrm{H}$ bond lengths are much shorter at structurally frozen adsorption sites, which results in significantly higher ZPEs. Since the zeolite clusters give bond lengths comparable to those of the fully relaxed crownethers, the effect should be much smaller there. Accordingly, adsorption energies at the zeolite cluster models were corrected for zero-point vibrational energy (ZPE) using results from partial frequency analysis of the adsorbed molecule in the field of the frozen adsorption site.

The crown-ether models were constructed from scratch and optimized. After addition of the $\mathrm{H}_{2}$, a full relaxation and analytical harmonic frequency analysis was performed. Adsorption ZPEs were calculated as the difference in the ZPEs of the fully relaxed species.

Relaxed potential energy surface scans used DFToptimized geometries and single points performed at the DLPNO-CCSD(T) level ${ }^{39}$ using NormalPNO settings ${ }^{40}$ and the def2-TZVPP basis set. For the $\mathrm{M}-\mathrm{H}_{2}$ curve of the $\mathrm{Au}^{+}$ complexes and distances below $170 \mathrm{pm}$, also the $\mathrm{H}-\mathrm{H}$ distances were constrained in steps of $10 \mathrm{pm}$ or smaller and for each $\mathrm{M}-\mathrm{H}_{2}$ distance the $\mathrm{H}-\mathrm{H}$ distance with the lowest DLPNO-CCSD(T) energy was chosen. This was done to avoid biasing the DLPNO-CCSD $(\mathrm{T})$ energies with incorrect structural parameters.

Bader analysis ${ }^{41}$ was performed using the Amsterdam Density Functional program (ADF, version 2019.103 r75513). ${ }^{42}$ Single point calculations were carried out on the ORCA-optimized structures using the PBEo functional and the $\mathrm{TZ}_{2} \mathrm{P}$ basis set with native Slater-type orbitals. ${ }^{43}$

\section{ASSOCIATED CONTENT}

Supporting Information Available: (1) additional plots and data on adsorption of $\mathrm{CO}$ and ethene; (2) optimized geometries and (3) corresponding energies, zero-point energies, vibrational frequencies and ligand bond lengths; (4) geometries and (5/6) energies from potential energy surface scans and (7) data from Bader analysis. This material is available free of charge via the Internet at http://pubs.acs.org.

\section{AUTHOR INFORMATION}

\section{Corresponding Author}

*E-mail: thomas.heine@tu-dresden.de

\section{Author Contributions}

All calculations and data analyses have been carried out by TW. Both authors discussed the results and contributed writing the manuscript.

\section{Funding Sources}

TW thanks the European Social Fund for a PhD fellowship. 


\section{ACKNOWLEDGMENT}

We thank the Center for Information Services and High Performance Computing (ZIH) at TU Dresden for computational resources.

\section{REFERENCES}

\section{References}

(1) Cejka, J.; van Bekkum, H.; Corma, A. Introduction to Zeolite Molecular Sieves, 3. Aufl.; Studies in Surface Science and Catalysis v.168; Elsevier professional: s.l., 2007.

(2) Vermeiren, W.; Gilson, J.-P. Impact of Zeolites on the Petroleum and Petrochemical Industry. Top Catal 2009, 52, 1131-1161.

(3) Martínez, C.; Corma, A. Inorganic molecular sieves: Preparation, modification and industrial application in catalytic processes. Coordination Chemistry Reviews 2011, $255,1558-1580$.

(4) Primo, A.; Garcia, H. Zeolites as catalysts in oil refining. Chemical Society reviews 2014, 43, 7548-7561.

(5) Yuna, Z. Review of the Natural, Modified, and Synthetic Zeolites for Heavy Metals Removal from Wastewater. Environmental Engineering Science 2016, 33, 443-454.

(6) van Speybroeck, V.; Hemelsoet, K.; Joos, L.; Waroquier, M.; Bell, R. G.; Catlow, C. R. A. Advances in theory and their application within the field of zeolite chemistry. Chemical Society reviews 2015, 44, 7044-7111.

(7) Pidko, E. A.; Hensen, E.J.M. Computational Chemistry of Zeolite Catalysis. Zeolites and Zeolite-Like Materials; Elsevier, 2016; pp 111-135.

(8) Li, G.; Pidko, E. A. The Nature and Catalytic Function of Cation Sites in Zeolites: a Computational Perspective. ChemCatChem 2019, 11, 134-156.

(9) Serykh, A. I.; . Kazansky, V. B. Unusually strong adsorption of molecular hydrogen on $\mathrm{Cu}+$ sites in coppermodified ZSM-5. Physical chemistry chemical physics : PCCP 2004, 6, 5250.

(10) Kazansky, V. B.; Pidko, E. A. A new insight in the unusual adsorption properties of $\mathrm{Cu}+$ cations in $\mathrm{Cu}-\mathrm{ZSM}-5$ zeolite. Catalysis Today 2005, 110, 281-293.

(11) Georgiev, P. A.; Albinati, A.; Eckert, J. Room temperature isosteric heat of dihydrogen adsorption on $\mathrm{Cu}(\mathrm{I})$ cations in zeolite ZSM-5. Chemical Physics Letters 2007, $449,182-185$.

(12) Ramirez-Cuesta, A. J.; Mitchell, P.C.H. Hydrogen adsorption in a copper ZSM5 zeoliteAn inelastic neutron scattering study. Catalysis Today 2007, 120, 368-373.
(13) Kim, C. W.; Heo, N. H.; Seff, K. Framework Sites Preferred by Aluminum in Zeolite ZSM-5. Structure of a Fully Dehydrated, Fully Cs + -Exchanged ZSM-5 Crystal (MFI, Si/Al = 24). J. Phys. Chem. C 2011, 115, 2482324838.

(14) Xing, B.; Ma, J.; Li, R.; Jiao, H. Location, distribution and acidity of $\mathrm{Al}$ substitution in ZSM-5 with different $\mathrm{Si} / \mathrm{Al}$ ratios - a periodic DFT computation. Catal. Sci. Technol. 2017, 7, 5694-5708.

(15) Knott, B. C.; Nimlos, C. T.; Robichaud, D. J.; Nimlos, M. R.; Kim, S.; Gounder, R. Consideration of the Aluminum Distribution in Zeolites in Theoretical and Experimental Catalysis Research. ACS Catal. 2018, 8, 770-784.

(16) Sklenak, S.; Dedecek, J.; Li, C.; Wichterlová, B.; Gábová, V.; Sierka, M.; Sauer, J. Aluminium siting in the ZSM-5 framework by combination of high resolution 27Al NMR and DFT/MM calculations. Physical chemistry chemical physics : PCCP 2009, 11, 1237-1247.

(17) Smit, B.; Maesen, T. L. M. Towards a molecular understanding of shape selectivity. Nature 2008, 451, 671678.

(18) Nachtigallová, D.; Bludský, O.; Otero Areán, C.; Bulánek, R.; Nachtigall, P. The vibrational dynamics of carbon monoxide in a confined space-CO in zeolites. Physical chemistry chemical physics : PCCP 2006, 8, 48494852.

(19) Göltl, F.; Hafner, J. Structure and properties of metalexchanged zeolites studied using gradient-corrected and hybrid functionals. III. Energetics and vibrational spectroscopy of adsorbates. The Journal of chemical physics $\mathbf{2 0 1 2}$, $136,64503$.

(20) Fagiani, M. R.; Song, X.; Debnath, S.; Gewinner, S.; Schöllkopf, W.; Asmis, K. R.; Bischoff, F. A.; Müller, F.; Sauer, J. Dissociative Water Adsorption by Al3O4+ in the Gas Phase. The journal of physical chemistry letters 2017, 8, 1272-1277.

(21) Lokare, K. S.; Braun-Cula, B.; Limberg, C.; Jorewitz, M.; Kelly, J. T.; Asmis, K. R.; Leach, S.; Baldauf, C.; Goikoetxea, I.; Sauer, J. Structure and Reactivity of Al$\mathrm{O}(\mathrm{H})-\mathrm{Al}$ Moieties in Siloxide Frameworks: Solution and Gas-Phase Model Studies. Angewandte Chemie (International ed. in English) 2019, 58, 902-906.

(22) Kemper, P. R.; Weis, P.; Bowers, M. T.; Maître, P. Origin of Bonding Interactions in $\mathrm{Cu}+(\mathrm{H} 2) \mathrm{n}$ Clusters: An Experimental and Theoretical Investigation. J. Am. Chem. Soc. 1998, 120, 13494-13502.

(23) Dryza, V.; Poad, B. L. J.; Bieske, E. J. Attaching molecular hydrogen to metal cations: perspectives from gas- 
phase infrared spectroscopy. Physical chemistry chemical physics : PCCP 2012, 14, 14954-14965.

(24) Bludský, O.; Nachtigall, P.; Čičmanec, P.; Knotek, P.; Bulánek, R. Characterization of the $\mathrm{Cu}+$ sites in MFI zeolites: combined computational and experimental study. $\mathrm{Ca}$ talysis Today 2005, 100, 385-389.

(25) Ozin, G. A.; Ozkar, S. Zeolates: a coordination chemistry view of metal-ligand bonding in zeolite guest-host inclusion compounds. Chem. Mater. 1992, 4, 511-521.

(26) Crabtree, R. H. Dihydrogen Complexation. Chemical reviews 2016, 116, 8750-8769.

(27) Otero Areán, C.; Manoilova, O. V.; Bonelli, B.; Rodrı\&\#x; guez Delgado, M.; Turnes Palomino, G.; Garrone, E. Thermodynamics of hydrogen adsorption on the zeolite Li-ZSM-5. Chemical Physics Letters 2003, 370, 631-635.

(28) Nachtigall, P.; Garrone, E.; Palomino, G. T.; Delgado, M. R.; Nachtigallová, D.; Areán, C. O. FTIR spectroscopic and computational studies on hydrogen adsorption on the zeolite Li-FER. Physical chemistry chemical physics :

PCCP 2006, 8, 2286-2292.

(29) Fagiani, M. R.; Song, X.; Petkov, P.; Debnath, S.; Gewinner, S.; Schöllkopf, W.; Heine, T.; Fielicke, A.; Asmis, K. R. Structure and Fluxionality of B13+ Probed by Infrared Photodissociation Spectroscopy. Angewandte Chemie (International ed. in English) 2017, 56, 501-504.

(30) Fagiani, M. R.; Liu Zeonjuk, L.; Esser, T. K.; Gabel, D.; Heine, T.; Asmis, K. R.; Warneke, J. Opening of an icosahedral boron framework: A combined infrared spectroscopic and computational study. Chemical Physics Letters 2015, 625, 48-52.

(31) Neese, F. The ORCA program system. WIREs Comput Mol Sci 2012, 2, 73-78.

(32) Neese, F. Software update: the ORCA program system, version 4.0. WIREs Comput Mol Sci 2018, 8, e1327.

(33) Adamo, C.; Barone, V. Toward reliable density functional methods without adjustable parameters: The PBE0 model. The Journal of chemical physics 1999, 110, 61586170 .
(34) Grimme, S.; Ehrlich, S.; Goerigk, L. Effect of the damping function in dispersion corrected density functional theory. Journal of computational chemistry 2011, 32, 1456-1465.

(35) Weigend, F.; Ahlrichs, R. Balanced basis sets of split valence, triple zeta valence and quadruple zeta valence quality for H to Rn: Design and assessment of accuracy. Physical chemistry chemical physics : PCCP 2005, 7, 3297-3305.

(36) Baerlocher, C.; McCusker, L. B. Database of Zeolite Structures. http://www.iza-structure.org/databases/ (accessed July 22, 2019).

(37) Weinrauch, I.; Savchenko, I.; Denysenko, D.; Souliou, S. M.; Kim, H.-H.; Le Tacon, M.; Daemen, L. L.; Cheng, Y.; Mavrandonakis, A.; Ramirez-Cuesta, A. J.; et al. Capture of heavy hydrogen isotopes in a metal-organic framework with active $\mathrm{Cu}(\mathrm{I})$ sites. Nature communications 2017, 8, 14496.

(38) Sillar, K.; Hofmann, A.; Sauer, J. Ab initio study of hydrogen adsorption in MOF-5. J. Am. Chem. Soc. 2009, $131,4143-4150$.

(39) Riplinger, C.; Sandhoefer, B.; Hansen, A.; Neese, F. Natural triple excitations in local coupled cluster calculations with pair natural orbitals. The Journal of chemical physics 2013, 139, 134101.

(40) Liakos, D. G.; Sparta, M.; Kesharwani, M. K.; Martin, J. M. L.; Neese, F. Exploring the Accuracy Limits of Local Pair Natural Orbital Coupled-Cluster Theory. Journal of chemical theory and computation 2015, 11, 15251539.

(41) Rodríguez, J. I.; Bader, R. F.W.; Ayers, P. W.; Michel, C.; Götz, A. W.; Bo, C. A high performance gridbased algorithm for computing QTAIM properties. Chemical Physics Letters 2009, 472, 149-152.

(42) ADF 2019.1; SCM, Theoretical Chemistry, Vrije Universiteit, Amsterdam, The Netherlands.

(43) van Lenthe, E.; Baerends, E. J. Optimized Slater-type basis sets for the elements 1-118. Journal of computational chemistry 2003, 24, 1142-1156. 


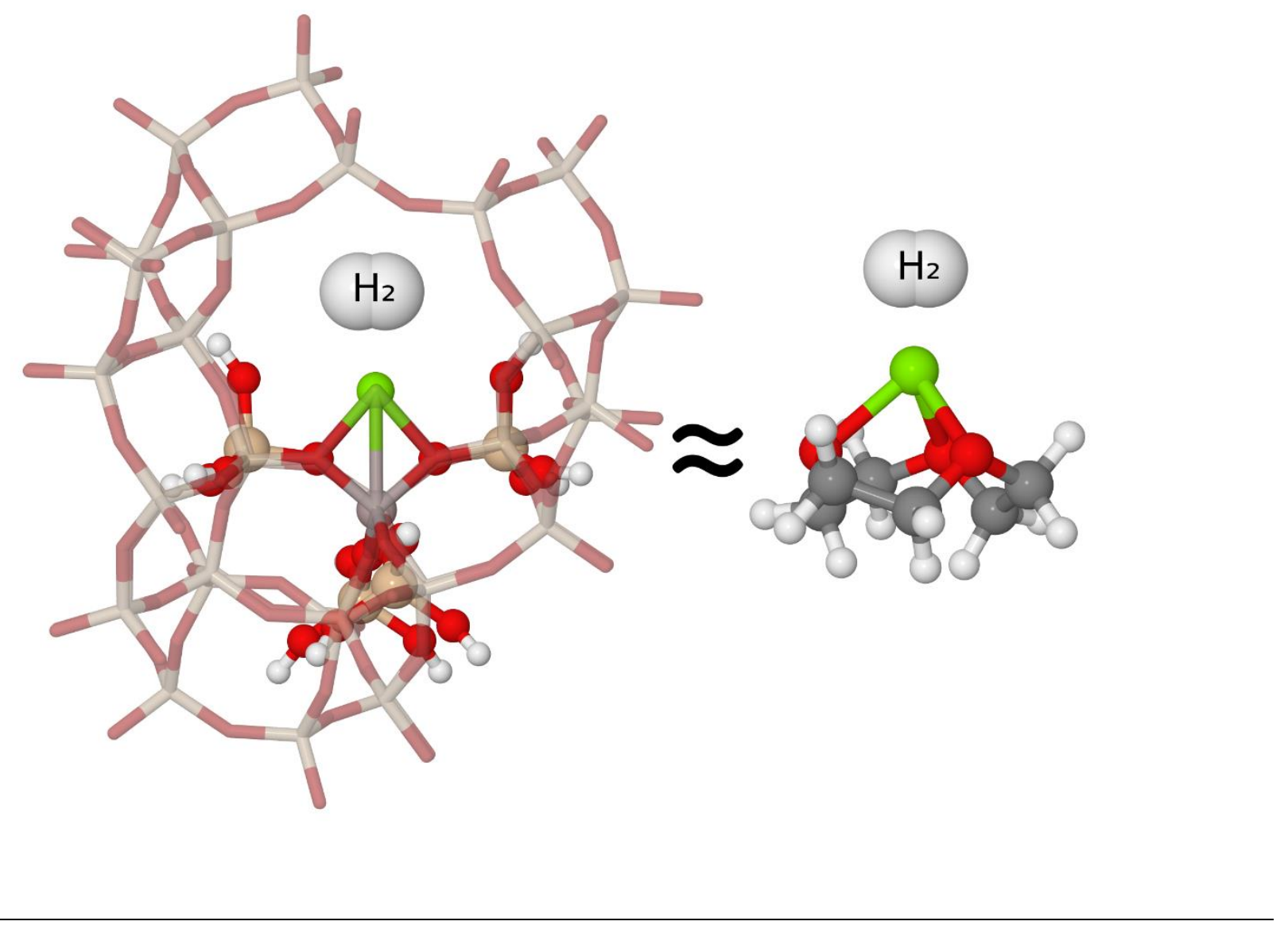

9 
Additional plots of the correlation of frequencies and adsorption energies of $\mathrm{H}_{2}$ at crown-ethers and zeolites

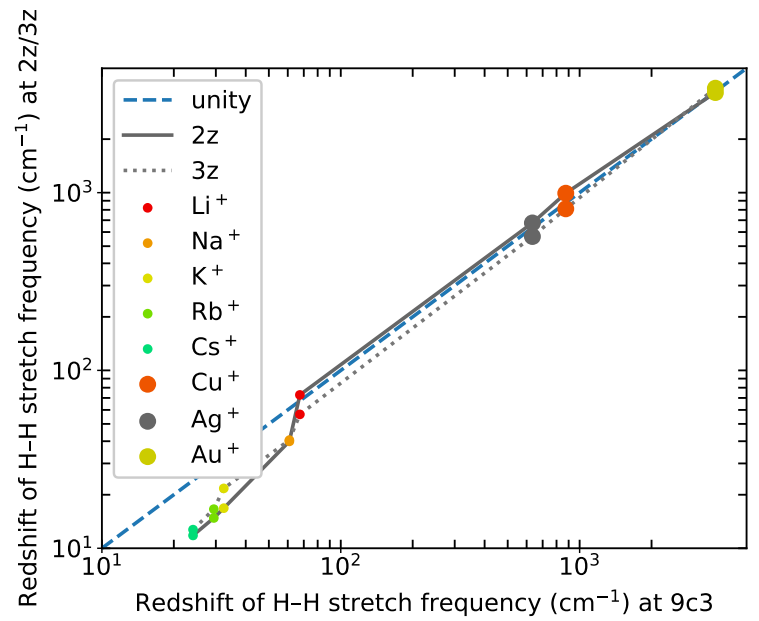

Figure $\mathrm{S}$ 1. Correlation of the shift of the $\mathrm{H}-\mathrm{H}$ stretch frequency between the molecular 9-crown-3 model system and the zeolite cluster models in log-log representation.

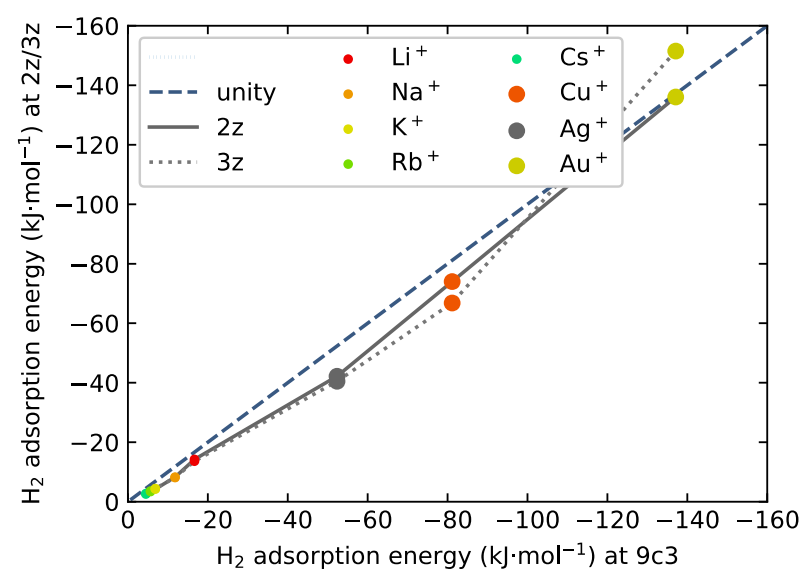

Figure $\mathrm{S}$ 2. Correlation of the $\mathrm{H}_{2}$ adsorption at 9-crown-3 and the zeolite cluster models.
Influence of the frozen-adsorption site approach on the zero-point energy of adsorbed $\mathrm{H}_{2}$

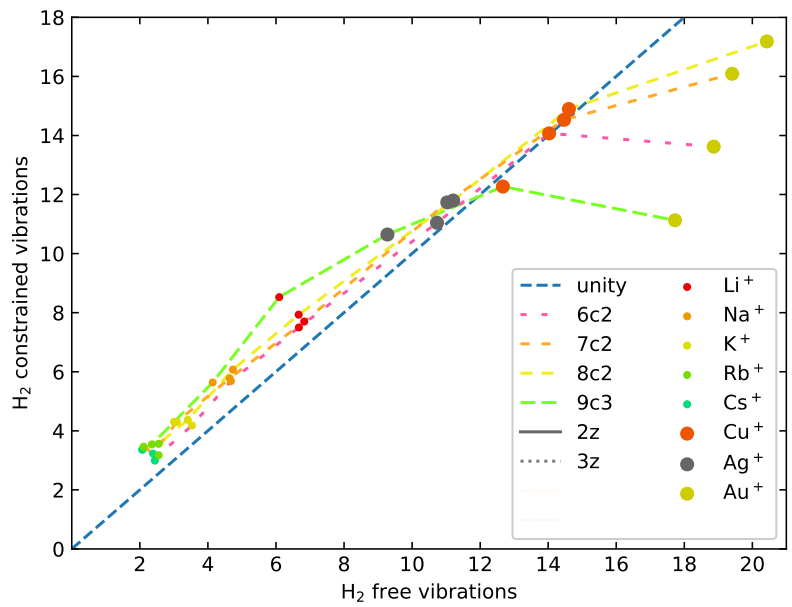

Figure $\mathrm{S}$ 3. Comparison of the zero-point vibrational energy calculated $(x)$ with full relaxation and full analytic harmonic vibrational frequency analysis and $(y)$ with rigid crown-ether (including the metal cation), relaxation only of the adsorbed molecule and partial numerical vibrational frequency analysis.

\section{Beyond $\mathrm{H}_{2}$ adsorption}

Both $\mathrm{CO}$ and ethene adsorb significantly more strongly than $\mathrm{H}_{2}$ giving them the potential to influence the geometry of the adsorption site more strongly. For example, $\mathrm{CO}$ is known to favor $2 \mathrm{z}$-like environments and to distort $3 \mathrm{z}$ like structures into $2 \mathrm{z}$-like ones to accommodate for this preference (Bludsky2005, 10.1016/j.cattod.2004.09.070, Bolis2004, 10.1021/jp049613e). Since a thorough examination of this effect is beyond the scope of this article, we take the similarity between the results from the $2 \mathrm{z}$ and $3 \mathrm{z}$ models as an indication that both can serve as reasonable zeroorder benchmarks to compare the crown-ether complexes against.

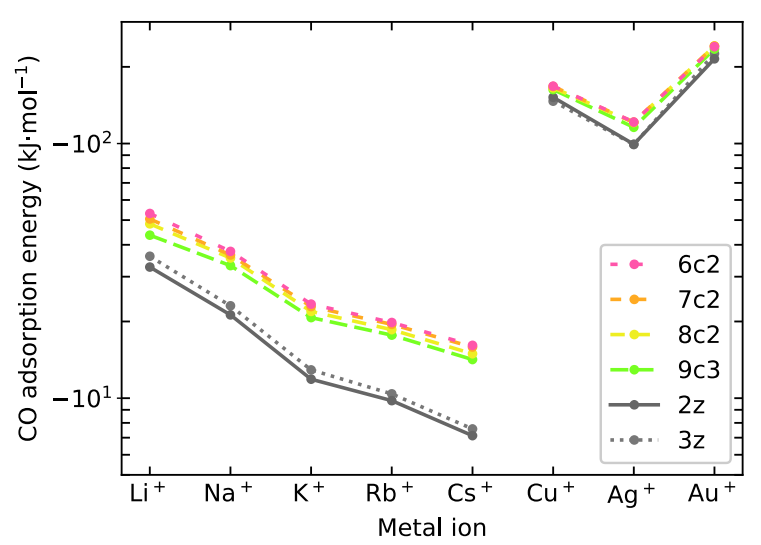

Figure $\mathrm{S}_{4}$. $\mathrm{CO}$ adsorption energy as function of the metal ion.

Overall, $\mathrm{CO}$ and ethene adsorption energies at crownether complexes are similar to those at the zeolite cluster 
models. A good correlation is also found for the $\mathrm{C}=\mathrm{C}$ stretch frequencies of ethene. For $\mathrm{C}=\mathrm{O}$ stretch frequencies, crown-ethers show the same tendencies as zeolites, albeit big quantitative differences probably preclude any useful application of the analogy for $\mathrm{CO}$.

\section{CO adsorption}

Unlike $\mathrm{H}_{2}$, $\mathrm{CO}$ coordinates to the cations end-on via the carbon atom. As in the case for $\mathrm{H}_{2}$, adsorption energies are similar for the crown-ether and the zeolite models (see Figure $\mathrm{S} 4$ ). Coordination is dominated by $\sigma$ donation as shown by the $\mathrm{C}=\mathrm{O}$ bond lengths and stretch frequencies, which differ from the value of the free molecule by less than $1 \mathrm{pm}$ and $90 \mathrm{~cm}^{-1}$, respectively.

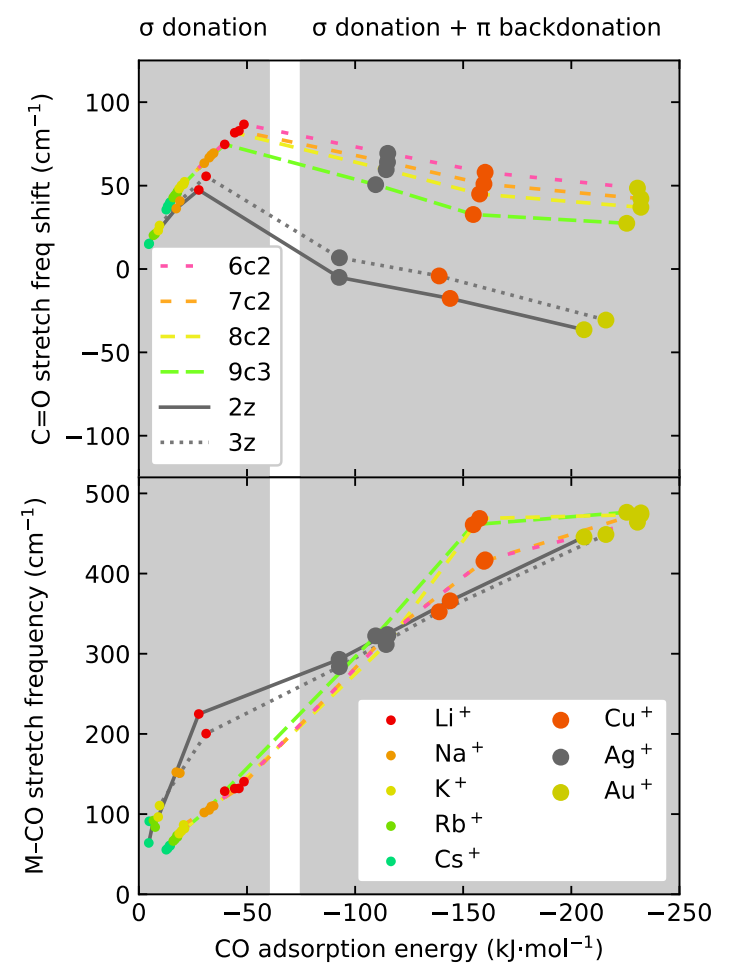

Figure $\mathrm{S}_{5}$. Correlation of the $\mathrm{C}=\mathrm{O}$ stretch frequency, $v_{\mathrm{CO}}$, and the $\mathrm{M}-\mathrm{CO}$ stretch frequency, $v_{\mathrm{M}-\mathrm{CO}}$, with the adsorption energy of $\mathrm{CO}$.

Figure $\mathrm{S} 5$ shows how the $\mathrm{C}=\mathrm{O}$ stretch frequency correlates with the adsorption energy of $\mathrm{CO}$. The complex relationship is explained by the fact that the $\mathrm{C}=\mathrm{O}$ stretch frequency, $v_{\mathrm{CO}}$, of carbonyl ligands is determined by the interplay of $\sigma$ donation (which reduces electron density on the carbon and thereby strengthens the $\mathrm{C}=\mathrm{O}$ bond) and $\pi$ backdonation (which increases electron density in the anti-bonding $\mathrm{C}=\mathrm{O} \pi$ orbitals and weakens it). Since alkali cations cannot partake in $\pi$ backdonation due to lack of valence $d$ orbitals, $v_{\mathrm{CO}}$ increases with increasing adsorption energy for these ions. By contrast, the low oxidation states of the coinage metal ions lead to a strong $\pi$ backdonation and therefore lower $v_{\mathrm{CO}}$. Although both types of models share this property, the effect is stronger for zeolite models than for the crown-ethers due to the net positive charge of the latter. Overall, the quantitative differences are too pronounced to consider crown-ether complexes suitable model systems for adsorption sites in zeolites when employing the $\mathrm{C}=\mathrm{O}$ stretch frequency as characteristic feature.

By contrast, $v_{\mathrm{M}-\mathrm{co}}$ shows a direct positive (albeit not linear) correlation with the $\mathrm{CO}$ adsorption energy. It might therefore serve as a more suitable measure of the strength of the $\mathrm{CO}$ adsorption.

\section{Ethene adsorption}

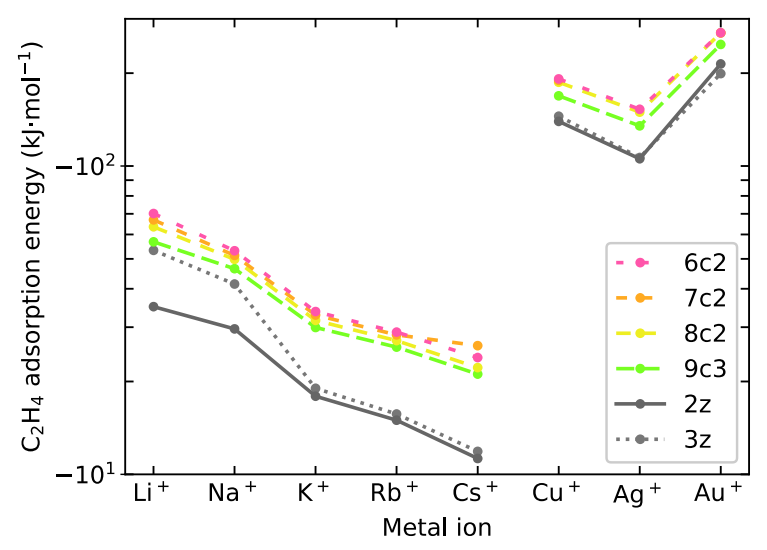

Figure S 6. Adsorption energy of ethene as a function of the metal ion.

Ethene combines a strong interaction like the one observed for $\mathrm{CO}$ with the side-on coordination mode seen in $\mathrm{H}_{2}$. Figure $\mathrm{S} 6$ shows the trends of the ethene adsorption energies along the periodic table. Similar to what is observed in both $\mathrm{H}_{2}$ and $\mathrm{CO}$, the crown-ether molecules follow the same trend as the zeolite clusters. What sets ethene apart is its $\pi$ electron system, which makes it a stronger Lewis base. Of the three gas molecules, it therefore shows the strongest preference for crown-ethers vs zeolites, because their net positive charge makes the former the stronger Lewis acids.

The most characteristic and accessible vibrational mode of ethene is the $C=C$ stretch vibration. Figure $S_{7}$ shows the strong correlation of the corresponding vibrational frequency between ethene bound at 9-crown-3 and ethene bound at the $2 \mathrm{z}$ zeolite cluster model. This correlation breaks down only for gold, which is predicted to interact more strongly than the other metal ions examined. 


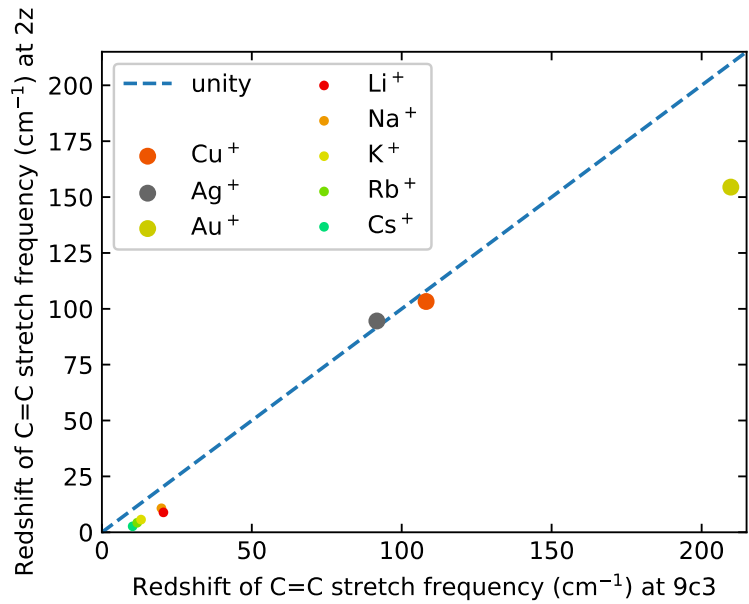

Figure $\mathrm{S} 7$. Correlation of the $\mathrm{C}=\mathrm{C}$ stretch frequency between 9 -crown- 3 and the $2 \mathrm{z}$ zeolite model. 